ISSN Print : 1411 - 951 X, ISSN Online : 20503-1716

Jurnal Ergonomi Indonesia

(The Indonesian Journal of Ergonomic)

Vol.3, No.1 : 1 Januari-Juni 2017

\title{
APLIKASI ERGONOMI PADA SERAGAM OLAHRAGA DAPAT MENINGKATKAN KENYAMANAN DAN MEMPERBAIKI RESPON SUHU KULIT KETIKA BEROLAHRAGA PADA SISWA SMP DI SMP "KESUMA SARI" DENPASAR BALI
}

\author{
${ }^{1}$ Suci Wahyu Ismiyasa, ${ }^{2}$ I Nyoman Adi Putra, ${ }^{3}$ Ketut Tirtayasa, ${ }^{4}$ Susy Purnawati \\ 1. Mahasiswa Program Studi Magister Ergonomi Fisiologi Kerja Universitas Udayana \\ 2. Staff Dosen Program Studi Magister Ergonomi Fisiologi Universitas Udayana \\ 3. Staff Dosen Program Studi Magister Ergonomi Fisiologi Universitas Udayana \\ 4. Staff Dosen Program Studi Magister Ergonomi Fisiologi Universitas Udayana
}

suciwahyuismiyasa@gmail.com

\begin{abstract}
ABSTRAK
Pemilihan seragam olahraga disesuaikan dengan aktivitas olahraga yang dilakukan. Untuk itu pemilihannya haruslah nyaman digunakan, menyerap keringat, adanya sirkulasi antara pakaian dengan kulit, ukuran seragam yang sesuai digunakan dengan harga yang murah dan terjangkau. Penelitian ini dilakukan untuk mengkaji secara terukur penerapan aplikasi ergonomi pada seragam olahraga dapat mewujudkan kenyamanan dalam berolahraga pada siswa SMP.

Desain penelitian ini menggunakan rancangan pretest-posttest control group design melibatkan 2 kelompok subjek yaitu Kelompok Kontrol dan Kelompok Perlakuan masingmasing berjumlah 12 orang sampel. Penelitian dilakukan di SMP Kesuma Sari, Sesetan, Denpasar, Bali. Data yang diukur adalah umur, tinggi badan, berat badan, suhu lingkungan, kuesioner kenyamanan berpakaian, respon suhu kulit dan respon denyut nadi pemulihan.

Hasil analisis deskriptif pada penelitian ini menunjukkan adanya perbedaan bermakna $(\mathrm{p}<0,05)$ pada variabel kenyamanan dan suhu permukaan kulit, tidak ada perbedaan bermakna $(p>0,05)$ pada variabel denyut nadi pemulihan. Nilai rerata selisih kenyamanan sebelum dan sesudah Kelompok Kontrol terjadinya penurunan sebesar $(-4,17 \pm 4,668)$ dan pada Kelompok Perlakuan terjadi peningkatan sebesar $(2,50 \pm 3,477)$. Nilai rerata selisih suhu kulit sebelum dan sesudah Kelompok Kontrol terjadi peningkatan suhu sebesar $\left(0,57^{\circ} \mathrm{C} \pm 0,64\right)$ dan pada Kelompok Perlakuan terjadi peningkatan suhu sebesar $\left(0,01^{\circ} \mathrm{C} \pm 0,65\right)$. Rerata penurunan denyut nadi pemulihan pada Kelompok Kontrol $(107,03 \pm 15,19)$ dan Kelompok Perlakuan $(106,93 \pm 16,37)$ tidak jauh berbeda sehingga tidak ada pengaruh diantara keduanya.

Disimpulkan bahwa aplikasi ergonomi pada seragam olahraga meningkatkan kenyamanan dalam berolahraga pada siswa SMP, aplikasi ergonomi seragam olahraga memperbaiki respon suhu kulit dalam berolahraga pada siswa SMP, dan aplikasi ergonomi seragam olahraga tidak ada pengaruh terhadap respon denyut nadi pemulihan dalam berolahraga pada siswa SMP.
\end{abstract}

Kata kunci: Seragam olahraga, kenyamanan berpakaian, respon suhu kulit, dan respon denyut nadi pemulihan 
ISSN Print : 1411 - 951 X, ISSN Online : 20503-1716

Jurnal Ergonomi Indonesia

(The Indonesian Journal of Ergonomic)

Vol.3, No.1 : 1 Januari-Juni 2017

\begin{abstract}
THE ERGONOMIC APPLICATIONS IN SPORTS UNIFORMS THAT CAN IMPROVE COMFORT AND IMPROVE THE RESPONSE OF SKIN TEMPERATURE IN EXERCISING ON THE JUNIOR HIGH SCHOOL STUDENTS AT SMP “KESUMA SARI” IN DENPASAR BALI
\end{abstract}

The choice of sports uniforms should be tailored to the sports activities undertaken. For that reason, the selection of uniforms should be comfortable to use, absorb sweat, and have a circulation between clothing and skin, fit uniform size and at affordable price. The study was conducted to examine the measured application of ergonomic applications on sports uniforms that can make comfort in exercising found on junior high school students.

The design of the study used pretest-posttest control group design involving 2 groups of subjects namely the Control Group and the Treatment Group of respectively 12 samples. The research was conducted at Kesuma Sari Junior High School, Sesetan, Denpasar, Bali. The measured data were age, height, body weight, ambient temperature, dress comfort questionnaire, skin temperature response and pulse recovery response.

The findings of descriptive analysis showed significant differences $(p<0.05)$ on the variables of comfort and surface temperature of the skin, no significant difference $(p>0.05)$ on the variable of pulse recovery. The mean value of the difference of comfort before and after exercising in the Control Group decreased by $(-4.17 \pm 4.668)$ and in the Treatment Group increased by $(2.50 \pm 3.477)$. The mean value of the skin temperature difference before and after exercising in the Control Group increased the temperature by $\left(0.57^{\circ} \mathrm{C} \pm 0.64\right)$ and in the Treatment Group there was a temperature increase of $\left(0.01{ }^{\circ} \mathrm{C} \pm 0.65\right)$. The Mean decrease in the pulse recovery in the Control $(107.03 \pm 15.18)$ and the Treatment Groups $(106.93 \pm 16.37)$ was not much different so there is no influence between the two.

It can be concluded that the ergonomic application of sport uniforms increased the comfort of exercise in the junior high school students of Kesuma sari, the ergonomics application of sport uniform may improve the skin temperature response in exercise on the junior high school students of Kesuma Sari, and the ergonomic application of sport uniform had no effect on the pulse recovery response in exercising on the students SMP Kesuma Sari.

Keywords: Sport uniform, dress comfort, skin temperature response, and pulse recovery respons 


\section{Jurnal Ergonomi Indonesia}

\section{(The Indonesian Journal of Ergonomic)}

\section{PENDAHULUAN}

Seragam merupakan pakaian yang digunakan untuk kegiatan bersama yang menjadi simbol identitas dalam suatu kelompok, instansi atau lembaga. Instansi pendidikan di Indonesia terdapat berbagai macam jenis seragam yaitu seragam nasional, seragam sekolah, seragam kepramukaan dan seragam olahraga. Pemilihan seragam olahraga disesuaikan dengan aktivitas olahraga yang dilakukan.

Menurut Reilly (2010), Desain seragam olahraga yang digunakan harus aman, efektif, nyaman, dan senang digunakan sehingga meningkatkan kapabilitas dan keterampilan seseorang. Kriteria desain seragam olahraga bermacam-macam tergantung pada kontak yang dibawa seperti kondisi lingkungan, elemen kinerja, resiko dari latihan dan kompetisinya merupakan bagian dari kriteria.

Ergonomi pada pakaian olahraga merupakan interaksi antara manusia dengan pakaian. Dengan cara mengoptimalkan kenyamanan dalam berolahraga, memaksimalkan gerakan dari pemakainya, memberikan proteksi dan menghindari luka lecet akibat gesekan (Bishop et al, 2013)

Pada umumnya jenis kain seragam olahraga terbuat dari bahan TC, PE dan Katun. Bahan TC dan PE kurang menyerap keringat tetapi lebih tahan lama. Berbeda dengan TC dan PE, bahan katun memiliki karakteristik halus, nyaman dipakai, lembut dan menyerap keringat (Fitinline, 2016).

Dalam merancang pengaplikasian ergonomi seragam olahraga disesuaikan dengan lamanya berolahraga, kualitas kain, warna, ukuran dan harga. Lamanya berolahraga tergantung dari mata pelajaran olahraga sesuai dengan kurikulum nasional SMP 2013. Kualitas kain yang dapat menyerap keringat. Agar menarik minat dan semangat siswa berolahraga dibutuhkan warna pakaian yang menarik. Ukuran pakaian mempengaruhi sirkulasi antara pakaian dengan tubuh dan norma kesopanan. Maka ukuran pakaian disesuaikan dengan antropometri tubuh siswa SMP. Harga yang murah tidak membebani pembelian seragam olahraga bagi orang tua atau wali murid.

\section{METODE PENELITIAN}

\section{Rancangan Penelitian}

Penelitian ini adalah penelitian eksperimental, menggunakan rancangan pretest-posttest control group design. Desain ini melibatkan dua kelompok subjek, satu diberi perlakuan eksperimen disebut Kelompok Perlakuan dan yang lain tidak diberi apa-apa disebut Kelompok Kontrol.

Tujuan penelitian ini untuk mengetahui dan membuktikan aplikasi ergonomi pada seragam olahraga terhadap kenyamanan, suhu kulit dan denyut nadi pemulihan.

\section{Populasi dan Sampel}

Populasi penelitian di bagi dengan dua kelompok. Pada Kelompok Kontrol berjumlah 12 orang dan Kelompok Perlakuan juga berjumlah 12 orang. Objeknya adalah siswa SMP Kesuma Sari di daerah Sesetan Denpasar Bali.

Teknik $\begin{aligned} & \text { penentuan } \\ & \text { sampel } \\ & \text { menggunakan } \\ & \text { sederhana. Dari jumlah populasi yang ada }\end{aligned}$
dipilih calon sampel yang memenuhi
kriteria inklusi. Jumlah sampel yang
dibutuhkan adalah 24 orang.


ISSN Print : $1411-951 \mathrm{X}$, ISSN Online : 20503-1716

Jurnal Ergonomi Indonesia

(The Indonesian Journal of Ergonomic)

Vol.3, No.1 : 1 Januari-Juni 2017

\section{Instrumen Penelitian}

Kenyamanan adalah perasaan fisiologis dari pemakai yang memakai pakaian di bawah kondisi lingkungan yang tepat. Pengukuran kenyamanan dengan menggunakan "Kuesioner Tingkat Kenyamanan Tubuh Terhadap Pakaian Olahraga". Penilaian secara subjektif yang dilakukan sebelum dan setelah sampel melakukan olahraga.

Suhu kulit merupakan suhu di permukaan kulit dengan mengukur menggunakan alat yaitu temperatur infrared dalam derajat Celcius diukur sebelum dan sesudah olahraga. Perbaikan respon suhu kulit dinyatakan oleh peningkatan suhu kulit yang tidak terlalu besar saat menyelesaikan olahraga. Bagian-bagian yang akan diukur adalah bagian depan badan yaitu dada dan perut, punggung yaitu punggung atas dan bawah, lengan yaitu lengan kanan dan kiri, dan paha yaitu paha kanan dan kiri.

Menghitung denyut nadi menggunakan denyut nadi pemulihan yang dikenal dengan metode brouha. Cara mengukurnya adalah hitung denyut nadi 30 detik setelah berolahraga selama 30 detik pada menit pertama, kemudian berhenti 30 detik, hitung kembali 30 detik untuk menit kedua dan seterusnya.

\section{HASIL PENELITIAN}

\section{Data Karakteristik Subjek}

Deskripsi karakteristik subjek penelitian disajikan pada Tabel 1 .

Tabel 1 Karakteristik Subjek Siswa SMP Kesuma Sari Denpasar Bali $(n=24)$

\begin{tabular}{cccc}
\hline Umur (th) & 12,83 & 0,76 & $12-14$ \\
$\begin{array}{c}\text { Tinggi } \\
\text { badan (cm) }\end{array}$ & 155,5 & 6,56 & $146-170$ \\
$\begin{array}{c}\text { Berat Badan } \\
(\mathrm{Kg})\end{array}$ & 45,96 & 5,03 & $35-58$ \\
Indeks & & & \\
Massa & 18,98 & 1,41 & $16,89-$ \\
Tubuh & & & 22,07 \\
$\left(\mathrm{Kg} / \mathrm{m}^{2}\right)$ & & & \\
\hline
\end{tabular}

Pada usia 12 tahun, anak sudah memiliki kemampuan untuk memahami informasi abstrak dan pada usia 14 tahun anak-anak sudah dapat mengambil kesimpulan dari informasi abstrak. Kondisi psikologi ini menjadikan anak-anak lebih mempercayai yang ada dalam pikirannya dan sulit untuk menerima sebuah pendapat tanpa alasan yang masuk akal. Anak-anak pun menjadi pribadi yang penentang baik guru maupun orang tua.

\section{Analisis Uji Normalitas dan Homogenitas Data}

Analisis uji normalitas menggunakan Shapiro-Wilk dan uji homogenitas menggunakan Levene Test

Dari berbagai variabel, variabel selisih denyut nadi menit ke 4 dan menit ke 5 mempunyai data yang berdistribusi tidak normal. Untuk data variabel rata-rata sesudah suhu kulit memiliki data yang tidak homogen.

\section{Analisis Kenyamanan Berpakaian}

Analisis data kenyamanan berpakaian diperoleh dengan kuesioner kenyamanan berpakaian yang disajikan pada Tabel 2.

Tabel 2 Hasil Analisis Data Kenyamanan Berpakaian

\begin{tabular}{ccc}
\hline \multirow{2}{*}{ Variabel } & $\begin{array}{c}\text { Kelompok } \\
\text { Kontrol }\end{array}$ & $\begin{array}{c}\text { Kelompok } \\
\text { Perlakuan }\end{array}$ \\
\cline { 2 - 3 } Nilai $\mathrm{p}$ \\
\cline { 2 - 3 } & Rerata $\pm \mathrm{SB}$ & Rerata $\pm \mathrm{SB}$ \\
\hline
\end{tabular}


ISSN Print : 1411 -951 X, ISSN Online : 20503-1716

\section{Jurnal Ergonomi Indonesia}

\section{(The Indonesian Journal of Ergonomic)}

\begin{tabular}{cccc}
\hline $\begin{array}{c}\text { Kenyamanan } \\
\text { Berpakaian } \\
\text { (Pre) }\end{array}$ & $45,08 \pm 5,961$ & $51,67 \pm 4,65$ & 0,006 \\
$\begin{array}{c}\text { Kenyamanan } \\
\text { Berpakaian } \\
\quad \text { Post) }\end{array}$ & $40,92 \pm 6,808$ & $54,17 \pm 4,52$ & 0,000 \\
$\quad$ Selisih & & 9 & \\
Kelompok & $-4,17 \pm 4,668$ & $2,50 \pm 3,477$ & 0,001 \\
\hline
\end{tabular}

Berdasarkan Tabel 3 menunjukan bahwa nilai variabel sebelum, setelah dan selisih mempunyai nilai $\mathrm{P}<0,05$ maka didapat kesimpulan Ho ditolak yaitu ada perbedaan yang signifikan di antara ke dua data Kelompok Kontrol dan Kelompok Perlakuan. Dengan rerata selisih Kelompok Kontrol $-4,17$ yaitu terjadi penurunan kenyamanan berpakaian dan rerata selisih Kelompok Perlakuan 2,50 yaitu terjadi peningkatan kenyamanan berpakaian.

\section{Analisis Respon Suhu Kulit}

Analisis data respon suhu kulit diperoleh dengan kuesioner kenyamanan berpakaian yang disajikan pada Tabel 3 .

Tabel 3 Hasil Analisis Data Suhu Kulit $\left({ }^{\circ} \mathrm{C}\right)$

\begin{tabular}{|c|c|c|c|}
\hline \multirow[t]{2}{*}{ Variabel } & $\begin{array}{c}\text { Kelompok } \\
\text { Kontrol }\end{array}$ & $\begin{array}{l}\text { Kelompok } \\
\text { Perlakuan }\end{array}$ & \multirow{2}{*}{$\begin{array}{c}\text { Nilai } \\
\text { p }\end{array}$} \\
\hline & Rerata \pm SB & Rerata & \\
\hline Rata-rata & & & \\
\hline $\begin{array}{l}\text { Suhu Kulit } \\
\text { (Pre) }\end{array}$ & $33,32 \pm 0,56$ & $33,10 \pm 0,96$ & 0,496 \\
\hline Rata-rata & & & \\
\hline $\begin{array}{l}\text { Suhu Kulit } \\
\text { (Post) }\end{array}$ & $33,88 \pm 0,28$ & $33,12 \pm 0,57$ & 0,001 \\
\hline $\begin{array}{c}\text { Selisih } \\
\text { Kelompok }\end{array}$ & $0,57 \pm 0,64$ & $0,01 \pm 0,65$ & 0,049 \\
\hline
\end{tabular}

Berdasarkan Tabel 4 menunjukan bahwa uji beda rerata suhu kulit sebelum intervensi antar Kelompok Kontrol dan Kelompok Perlakuan mendapatkan nilai $\mathrm{p}>0,05$ maka didapat kesimpulan Ho diterima yaitu tidak ada perbedaan yang signifikan di antara ke dua data tersebut. Hal ini artinya data suhu kulit sebelum intervensi antar ke dua kelompok adalah komparabel. Data uji beda suhu kulit sesudah dan selisih intervensi mempunyai
Vol.3, No.1 : 1 Januari-Juni 2017

nilai $\mathrm{p}<0,05$ maka didapat kesimpulan Ho ditolak yaitu ada perbedaan yang signifikan di antara ke dua data tersebut. Pada nilai Kelompok Kontrol terdapat peningkatan rerata suhu sebesar 0,57 dan pada nilai Kelompok Perlakuan terdapat peningkatan rerata suhu sebesar 0,01 .

\section{Analisis Respon Denyut Nadi Pemulihan}

Analisis data respon denyut nadi pemulihan dalam penelitian ini didapat dari pengukuran yang dilakukan sebelum berolahraga dan setelah berolahraga dapat dilihat pada Tabel 4

Tabel 4 Data Hasil Analisis Respon

Denyut Nadi Pemulihan(/menit)

\begin{tabular}{cccc}
\hline \multirow{2}{*}{ Variabel } & $\begin{array}{c}\text { Kelompok } \\
\text { Kontrol }\end{array}$ & $\begin{array}{c}\text { Kelompok } \\
\text { Perlakuan }\end{array}$ & \multirow{2}{*}{$\begin{array}{c}\text { Nilai } \\
\text { Rerata }\end{array}$} \\
\cline { 2 - 3 } & Rerata & $\mathrm{p}$ \\
\hline $\begin{array}{c}\text { Nadi } \\
\text { Awal }\end{array}$ & $90,50 \pm 5,402$ & $88 \pm 7,032$ & 0,339 \\
Nadi & $120,83 \pm 15,05$ & $128,33 \pm 17,369$ & 0,270 \\
Menit 1 \\
Nadi \\
Menit 2 \\
Nadi \\
Menit 3 \\
Nadi & $113,83 \pm 14,783$ & $116,33 \pm 16,813$ & 0,703 \\
Menit 4 & $102,17 \pm 15,314$ & $97,50 \pm 15,98$ & 0,473 \\
Nadi & $92,33 \pm 14,74$ & $89 \pm 14,206$ & 0,578 \\
Menit 5 & & & \\
\hline
\end{tabular}

Berdasarkan Tabel 4 menunjukan bahwa semua data uji mempunyai nilai $p>0,05$ maka didapat kesimpulan Ho diterima yaitu tidak ada perbedaan yang signifikan di antara ke dua data dengan berbagai variabel tersebut.

Tabel 5 Data Selisih Hasil Analisis Respon Denyut Nadi Pemulihan

\begin{tabular}{cccc}
\hline \multirow{2}{*}{ Variabel } & $\begin{array}{c}\text { Kelompok } \\
\text { Kontrol }\end{array}$ & $\begin{array}{c}\text { Kelompok } \\
\text { Perlakuan }\end{array}$ & Nilai p \\
\cline { 2 - 4 } & Rerata \pm SB & Rerata \pm SB & \\
\hline A & $7,00 \pm 5,625$ & $12,00 \pm 9,381$ & 0,128 \\
B & $7,83 \pm 6,520$ & $12,83 \pm 7,004$ & 0,840 \\
C & $3,83 \pm 3,243$ & $6,00 \pm 5,257$ & 0,237 \\
D & $9,83 \pm 8,376$ & $8,50 \pm 6,987$ & 0,727 \\
\hline
\end{tabular}

Keterangan: 


\section{Jurnal Ergonomi Indonesia}

\section{(The Indonesian Journal of Ergonomic)}

A: Denyut Nadi menit 1 - Denyut Nadi menit 2

B: Denyut Nadi menit 2 - Denyut Nadi menit 3

C: $\quad$ Denyut Nadi menit 3 - Denyut Nadi menit 4

D: Denyut Nadi menit 4 - Denyut Nadi menit 5

Berdasarkan Tabel 5 menunjukan bahwa semua data uji mempunyai nilai $\mathrm{p}>0,05$ maka didapat kesimpulan Ho diterima untuk data selisih respon denyut nadi pemulihan pada tiap menit yaitu tidak ada perbedaan yang signifikan di antara ke dua data dengan berbagai variabel tersebut.

\section{PEMBAHASAN}

\section{Karakteristik Subjek Penelitian}

Adapun subjek yang terlibat dalam penelitian ini merupakan anak SMP dengan rerata umur $13,47 \pm 0,68$ dan rentangan umur 12-14. Menurut Grandjean (2000) bahwa kondisi umur berpengaruh terhadap kemampuan kerja fisik atau kekuatan otot seseorang, sedangkan kemampuan fisik maksimal seseorang dicapai pada umur antara 25-35 tahun, baik laki-laki maupun perempuan dan terus menurun seiring bertambahnya umur. Tahapan tumbuh kembang dikatakan dengan masa remaja awal. Menurut Andriani dan Wirjatmadi (2012) bahwa pada masa ini proporsi lemak dan otot pada anak perempuan cenderung serupa dengan anak laki-laki, yaitu lemak tubuh sekitar $19 \%$ dari berat badan total pada anak perempuan dan $15 \%$ pada anak lakilaki.

Menurut Morris (2013) Indeks massa tubuh (IMT) merupakan instrumen objektif untuk mengukur resiko kesehatan dan dihitung berdasarkan perbandingan berat badan dalam satuan kilogram dengan kuadrat dari tinggi badan dalam satuan meter pada subjek yang bersangkutan. Pada tesis ini, indeks massa tubuh subjek berada pada rentangan 16,89-22,07 dengan rerata 18,98 $\pm 1,41$. Menurut Depkes (2010) indeks massa tubuh normal untuk kategori umur 12-14 tahun berada pada rentang 14,5-22,6. Maka indeks massa tubuh pada subjek penelitian ini berada dalam kategori sehat dan normal.

\section{Kenyamanan Berpakaian}

Berdasarkan analisis hasil

penelitian kenyamanan berpakaian dinyatakan bahwa ada perbedaan signifikan antara ke dua kelompok dilihat dari uji kemaknaan selisih dengan menggunakan Independent T-test $(p<0,05)$. Rerata sebelum dan sesudah Kelompok Kontrol 45,08 $\pm 5,961$ dan $40,92 \pm 6,808$ terjadi penurunan nilai kenyamanan sebesar 4,17 $\pm 4,668$. Sedangkan rerata sebelum dan sesudah

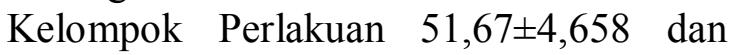
$54,17 \pm 4,529$ terjadi peningkatan kenyamanan sebesar 2,50 $\pm 3,477$.

Menurut Malik dan Sinha (2012), kenyamanan adalah berhubungan pada persepsi subjektif seseorang dari berbagai macam sensasi yang terdiri dari visual (kenyamanan estetik), termal (dingin dan hangat), nyeri (menusuk dan membuat gatal) dan sentuhan (lembut, kasar, halus dan kaku). Dalam penelitian ini persepsi dari subjek penelitian terhadap sentuhan dan termal dapat dilihat dari kuesioner pada lampiran I, yang mengatakan bahwa pakaian pada Kelompok Kontrol dan Kelompok Perlakuan dirasa nyaman dengan menggunakan skor tingkat kenyamanan.

Menurut Bartkowiak (2016), fisiologis kenyamanan bergantung pada pakaian yang digunakan, pengaruh yang paling penting datang dari struktur kain, jenis kain yang lembut dan struktur penyerapannya. Menurut Oral (2016), kenyamanan berpakaian berhubungan dengan kenyamanan termal, parameter paling penting dalam menentukan kenyamanan berpakaian adalah material dan tipe serabut.

Dari dua kelompok terdapat perbedaan struktur dan jenis kain seragam olahraga yang menentukan kenyamanan berpakaian. Di mana Kelompok Kontrol diberikan perlakuan dengan memakai 


\section{Jurnal Ergonomi Indonesia}

\section{(The Indonesian Journal of Ergonomic)}

seragam lama dengan bahan atasan polyester dan bawahannya menggunakan campuran jersey dan polyester. Kelompok Perlakuan diberikan perlakuan dengan memakai seragam baru dengan bahan atasan katun dan bawahan menggunakan tekstur bagian luar halus dan dalam berbulu.

Polyester merupakan serabut tekstil buatan dan katun merupakan serabut tekstil alami. Kedua bahan ini mempunyai perbedaan daya serap air dan tekstur yang berpengaruh terhadap kenyamanan seseorang ketika berolahraga. Menurut Firgo dkk (2006), kain dengan serabut natural seperti katun, wool dan serabut selulosa mempunyai penyerapan terbaik dan dapat bersirkulasi. Sedangkan kain dengan serabut sintesis tidak dapat menyerap air tetapi mempunyai kekuatan bahan dan mudah dirawat.

Dalam ilmu ergonomi olahraga, kesesuaian pakaian dengan jenis olahraga dapat mengoptimalkan performa dalam berolahraga. Siswa SMP akan mengenakan pakaian olahraga ketika pelajaran olahraga berlangsung. Jadwal mata pelajaran olahraga dilakukan sekali dalam seminggu. Dengan intensitas olahraga SMP ini, pakaian dengan serabut tekstil alami atau katun ini cocok untuk olahraga yang dilakukan.

Manfaat yang dirasakan dalam penelitian ini yaitu bisa menjadi tolak ukur antara ke dua bahan agar memilih bahan atasan dengan kualitas katun dan bawahan dengan kualitas halus dan berbulu bagian dalam. Penilaian ini di lihat segi kenyamanan dalam berpakaian ketika berolahraga di sekolah terutama SMP. Dalam hal ergonomi yang memperhatikan kaedah kenyamanan bekerja bagi penggunanya, kualitas bahan pakaian yang dikenakan oleh pemakainya juga dapat menjadi dasar penentuan, karena pakaian merupakan kebutuhan yang sangat pokok dan setiap ada manusia pasti ada pakaian yang dikenakan olehnya.

\section{Suhu Kulit}

Berdasarkan analisis hasil penelitian suhu kulit dinyatakan bahwa ada perbedaan signifikan antara ke dua kelompok dilihat dari uji kemaknaan selisih dengan menggunakan Independent $t$-Test $(\mathrm{p}<0,05)$. Rerata sebelum dan sesudah pada Kelompok Kontrol $33,32 \pm 0,56$ dan $33,88 \pm 0,28$ terjadi peningkatan suhu sebesar $0,57 \pm 0,64$ sedangkan Kelompok Perlakuan $33,10 \pm 0,96$ dan $33,12 \pm 0,57$ terjadi peningkatan suhu sebesar $0,01 \pm 0,65$.

Ketika berolahraga, tubuh akan menghasilkan panas akibat dari gerakan otot dan dikeluarkan melalui radiasi, konduksi dan penguapan air pada saluran napas dan kulit. Keseimbangan antara panas yang dihasilkan dan dikeluarkan menentukan suhu tubuh. (Ganong, 2014).

Suhu kulit berbeda dengan suhu inti tubuh, karena suhu kulit dipengaruhi oleh suhu yang ada di lingkungan sekitar tubuh. Ketika terjadinya perubahan suhu disekitar kulit mengakibatkan perubahan pada pembuluh darah bawah kulit. Lingkungan yang dingin mengubah pembuluh darah menjadi mengecil/vasokontriksi sedangkan lingkungan yang panas mengubah pembuluh darah menjadi membesar/vasodilatasi. Perubahan pembuluh darah ini diteruskan ke medulla spinalis untuk dikembalikan ke kulit dan kelenjar keringat (Sherwood, 2011).

Tubuh manusia yang tinggal di lingkungan yang lebih dingin daripada suhu tubuh akan terus menerus menghasilkan panas secara internal, agar dapat membantu mempertahankan suhu tubuh yang kita ketahui suhu inti sekitar $37,1^{\circ} \mathrm{C}$. Bukan hanya tubuh yang memproduksi panas tetapi juga dibantu oleh pakaian. Menurut Guyton (2011), pakaian membantu memperlambat pengeluaran panas kira-kira setengah dari tubuh yang tidak memakai pakaian. Efektivitas pakaian akan hilang ketika pakaian menjadi basah, karena konduktivitas air yang tinggi meningkatkan kecepatan pemindahan 


\section{Jurnal Ergonomi Indonesia}

\section{(The Indonesian Journal of Ergonomic)}

panas melalui pakaian hingga sebesar 20 kali lipat atau lebih.

Bagian-bagian tubuh memiliki suhu yang berlainan dan besar perbedaan suhu antara beberapa bagian tubuh dengan suhu lingkungan bervariasi. Ekstremitas umumnya lebih dingin daripada bagian tubuh lainnya. Suhu rektum dapat mencerminkan suhu inti tubuh (core temperatur) dan paling sedikit dipengaruhi oleh perubahan lingkungan. Suhu oral pada keadaan normal $0,5^{\circ} \mathrm{C}$ lebih rendah daripada suhu rektum, tetapi suhu oral ini banyak dipengaruhi oleh faktor seperti makanan atau minuman panas atau dingin, mengunyah permen karet, merokok, dan bernapas melalui mulut (Ganong, 1998).

Menurut Sherwood (2011), suhu kulit dapat berfluktuasi antara $68^{\circ} \mathrm{F}$ dan $104^{\circ} \mathrm{F}\left(20^{\circ} \mathrm{C}\right.$ dan $\left.40^{\circ} \mathrm{C}\right)$ tanpa mengalami kerusakan. Ini dilakukan tubuh sebagai tindakan kontrol agar membantu mempertahankan suhu inti yang konstan. Menurut Guyton (2011) bila dengan tibatiba reseptor dingin dipajankan pada penurunan suhu, mula-mula reseptor akan memudar dalam waktu beberapa detik pertama dan menjadi semakin lambat secara progresif selama 30 menit berikutnya atau lebih. Dengan kata lain, "adaptasi" reseptor ini sangat luas; tetapi tidak pernah 100 persen. Pada suhu kulit di bawah $20^{\circ} \mathrm{C}$ dan di atas $40^{\circ} \mathrm{C}$ tidak terjadi adaptasi, tetapi di antara suhu $20^{\circ} \mathrm{C}$ dan $40^{\circ} \mathrm{C}$ ada adaptasi, sehingga sensasi yang ditimbulkan oleh perubahan suhu secara perlahan-lahan menghilang dan menjadi suatu keadaan netralitas panas. Di atas $45^{\circ} \mathrm{C}$ mulai terjadi kerusakan jaringan dan sensasinya berubah menjadi nyeri.

Dengan intensitas olahraga yang dilakukan di SMP, seragam olahraga yang dikenakan ini memiliki respon suhu yang berbeda antara Kelompok Kontrol dan Kelompok Perlakuan. Pada Kelompok Kontrol terjadi peningkatan suhu sebesar $0,57 \pm 0,64$ dengan memakai seragam pada sekolah tersebut dengan bahan atasan polyester dan bawahannya menggunakan campuran jersey dan polyester. Sedangkan pada Kelompok Perlakuan terjadi peningkatan sebesar $0,01 \pm 0,65$ dengan memakai seragam dengan jenis bahan atasan katun dan bawahan menggunakan tekstur bagian luar halus dan dalam berbulu. Perbedaan peningkatan Kelompok Perlakuan sebesar 0,56 dari Kelompok Kontrol.

Kelompok Kontrol diberikan perlakuan dengan memakai seragam lama dengan bahan atasan polyester dan bawahannya menggunakan campuran jersey dan polyester. Bahan polyester adalah bahan yang tidak dapat menyerap keringat sehingga dapat menimbulkan kelembaban di antara kulit dan pakaian. Menurut Humphries (2009) bahan polyester memang tidak dapat menyerap keringat tetapi mempunyai kekuatan dalam jenis kainnya.

Kelompok Perlakuan diberikan perlakuan dengan memakai seragam baru dengan bahan atasan katun dan bawahan menggunakan tekstur bagian luar halus dan dalam berbulu. Bahan katun memiliki penyerapan keringat yang lebih baik dari polyester yang membuat kulit tetap kering dan tidak lembab mempunyai kekuatan yang cukup baik (Humphries, 2009).

Menurut Firgo dkk (2006), kain dengan serabut natural seperti katun, wool dan serabut selulosa mempunyai penyerapan terbaik dan memungkinkan sirkulasi udara pada pori-pori kain. Sedangkan kain dengan serabut sintesis tidak dapat menyerap air tetapi mempunyai kekuatan bahan dan mudah dirawat. Untuk itu penggunaan serabut natural sangat cocok digunakan untuk pakaian olahraga umum dan pakaian sehari-hari tetapi tidak cocok untuk pakaian olahraga dengan aktivitas yang tinggi dengan produksi keringat berlebih.

Penelitian ini serupa dengan yang dilakukan oleh Olesen's (1973) yang memakai pakaian kantor longgar dengan suhu lingkungan netral dan diukur memakai thermocouples taped pada kulit yang menunjukan rata-rata suhu kulit adalah $33,38^{\circ} \mathrm{C}$. Begitupun juga Zhang 


\section{Jurnal Ergonomi Indonesia}

\section{(The Indonesian Journal of Ergonomic)}

(2003) yang memakai pakaian ketat menutupi seluruh kulit dengan memakai pengukuran yang sama menunjukan ratarata suhu kulit adalah $34,45^{\circ} \mathrm{C}$.

Penelitian serupa juga dilakukan oleh peneliti Rahayu Astutik (2008) menyatakan bahwa pakaian olahraga dengan model terbuka dan tertutup memberikan pengaruh terhadap temperatur tubuh dan denyut nadi. Pakaian olahraga model tertutup menghasilkan suhu inti tubuh yang lebih tinggi dibandingkan pakaian olahraga model terbuka.

\section{Denyut Nadi}

Dari hasil analisis data denyut nadi pada Tabel 4 didapat bahwa nilai denyut nadi sebelum (Pre) antara kelompok (Kelompok Kontrol dan Kelompok Perlakuan) adalah tidak berbeda secara signifikan $(p>0,05)$. Hal ini menunjukan bahwa kondisi denyut nadi awal dari subjek adalah sama dan dapat disimpulkan bahwa tidak adanya perubahan denyut nadi antara seragam yang digunakan pada Kelompok Kontrol dan Kelompok Perlakuan.

Denyut nadi adalah frekuensi volume darah yang dipompa ke dalam aorta oleh jantung dalam satu menit. Denyut nadi mempunyai hubungan liner yang tinggi dengan asupan oksigen pada waktu kerja. Pengukuran denyut nadi dapat diestimasi dengan menggunakan denyut nadi pemulihan (heart rate recovery) atau dikenal dengan metode 'Brouha'. Keuntungan dari metode ini adalah sama sekali tidak mengganggu atau menghentikan pekerjaan, karena pengukuran dilakukan tepat setelah berhenti bekerja (Tarwaka, 2011).

Perubahan kardiovaskuler selama berolahraga akan meningkatkan aliran darah ke kulit, ini terjadi karena pusat kontrol suhu di hipotalamus memicu vasodilatasi arteriol kulit. Peningkatan aliran darah ke kulit membawa panas yang dihasilkan oleh otot ke permukaan tubuh untuk dikeluarkan ke lingkungan eksternal (Sherwood, 2011).
Aliran darah kulit sebagian besar dikendalikan oleh sistem saraf pusat melalui saraf simpatis. Aliran darah ke kulit sekitar $3 \mathrm{ml} /$ menit/100 g jaringan pada suhu sejuk, apabila diperlukan, perubahan nilai cukup besar dapat terjadi. Apabila manusia dipaparkan terhadap pemanasan tubuh, aliran darah kulit dapat meningkat berlipat ganda, mencapai 7 sampai $8 \mathrm{~L} /$ menit untuk seluruh tubuh. Apabila suhu tubuh diturunkan, aliran darah kulit berkurang, turun sampai sedikit di atas nol pada suhu yang sangat rendah. Meskipun terjadi vasokontriksi hebat, aliran darah kulit masih cukup besar untuk memenuhi kebutuhan dasar metabolik kulit (Guyton, 2011)

Respon suhu permukaan kulit mempunyai nilai perbedaan yang signifikan terhadap pakaian yang dilakukan pada penelitian ini, berbeda dengan respon denyut nadi pemulihan. Respon denyut nadi pemulihan mempunyai nilai perbedaan yang tidak signifikan terhadap pakaian. Ini terjadi karena pakaian tidak menambah beban kerja yang dapat mempengaruhi perubahan denyut nadi pemulihan dari ke dua kelompok yaitu Kelompok Kontrol dan Kelompok Perlakuan.

\section{SIMPULAN DAN SARAN}

\section{Simpulan}

Berdasarkan dari hasil analisis dan pembahasan pada bab sebelumnya, dapat disimpulkan bahwa:

1. Aplikasi ergonomi pada seragam olahraga meningkatkan kenyamanan dalam berolahraga pada siswa SMP Kesuma Sari

2. Aplikasi ergonomi pada seragam olahraga memperbaiki respon suhu kulit dalam berolahraga pada siswa SMP Kesuma Sari

3. Aplikasi ergonomi pada seragam olahraga tidak ada pengaruh terhadap respon denyut nadi pemulihan dalam berolahraga pada siswa SMP Kesuma Sari 
ISSN Print : $1411-951 \mathrm{X}$, ISSN Online : 20503-1716

Jurnal Ergonomi Indonesia

(The Indonesian Journal of Ergonomic)

Vol.3, No.1 : 1 Januari-Juni 2017

Saran

Berdasarkan pada simpulan di atas maka dapat disarankan beberapa hal sebagai berikut:

1. Kepada pihak sekolah dalam hal ini yang berwenang dalam merencanakan peralatan sekolah supaya memperhatikan kaedah ergonomi guna mewujudkan kondisi pakaian olahraga yang lebih nyaman.

2. Dalam mengukur suhu tubuh menggunakan suhu inti dan suhu permukaan kulit.

\section{DAFTAR PUSTAKA}

Andriani, M., dan Wirjatmadi, B. 2012. Peranan Gizi dalam Sirklus Kehidupan. Jakarta: Kencana Prenada Media Group.

Astutik, Rahayu. 2008. Pengaruh Berpakaian Olahraga Tertutup dan Berpakaian Olahraga Terbuka Terhadap Peningkatan Temperatur Tubuh, Peningkatan Denyut Nadi, Penurunan Kadar Asam Laktat dan Kelincahan Akibat Latihan Fisik (Penelitian Eksperimental). Jakarta: Universitas Airlangga.

Bartkowiak, Grazyna., Frydrynch, I., dan Greszta, A. 2016. Fabric Selection for the Reference Clothing Destined for Ergonomics Test of Protective Clothing: Physiological Comfort Point of View. Autex Research Journal, 256-261.

Bishop, P. A., Balilonis, G., Davis, J. K., and Zhang, Y. 2013. Ergonomics and Comfort in Protective and Sport Clothing. Ergonomics.

Depkes. 2010. Keputusan Menteri Kesehatan Republik Indonesia. Jakarta.

Firgo, H., Suchomel, F., and Burrow, T. 2006. Tencel High Performance Sportwear. Lenzinger Berichte, 4450.

Fitinline, 2016. 9 Jenis Kain Untuk Membuat Pakaian Olahraga. Tersedia dari URL: https://fitinline.com/article/read/9- jenis-kain-untuk-membuatpakaian-olahraga/. Tanggal akses 24 Maret 2016

Ganong, W. F. 2014. Buku Ajar Fisiologi Kedokteran. Jakarta: EGC.

Ganong, W.F. 1998. Buku Ajar Fisiologi Kedokteran. Jakarta: EGC.

Goldman, R. F. 2005. The Four 'Fs' of Clothing Comfort. In Y. Tochihara, \& T. Ohnaka, Environmental Ergonomics (pp. 315-319). Amsterdam: Elsevier.

Grandjean, E. 2000. Fitting the Task to The man. A Textbook of Occupational Ergonomics. London: Taylor and Francis Ltd.

Guyton dan Hall. 2011.Buku Ajar Fisiologi Kedokteran. Singapore: Elsevier.

Humphries, M. 2009. Textile Fiber. Canada: Prentice Hall.

Malik, T., and Sinha, T. K. 2012. Clothing Comfort: A key Parameter in Clothing. Shri Vaishnav Institute of Technology and Science, 53-57.

Morris, J. C. 2013. Pedoman Gizi Pengkajian dan Dokumentasi. Jakarta: EGC.

Olesen, B. W. dan P. O. Fanger. 1973. The Skin Temperature Distribution for Resting Man in Comfort. Arch. Sci. Physiology 27: A385 - A393

Oral, Oksan. 2016. An Investigation on the Thermal Comfort Properties of Textile Fabrics Made of CelluloseBased Fiber. Industria Textile, 387391.

Reilly, T. 2010. Ergonomics in Sport and Physical Activity. United State: Human Kinetics.

Sherwood, L. 2011. Fisiologi Manusia: dari sel ke sistem. Jakarta: Buku Kedokteran EGC.

Tarwaka. 2015. Ergonomi Industri: Dasar-dasar Pengetahuan Ergonomi dan Aplikasi di Tempat Kerja. Surakarta: Harapan Press.

Zhang, H. 2003. Human Thermal Sensation and Comfort in Transient and Non-Uniform Thermal 
ISSN Print : 1411 - 951 X, ISSN Online : 20503-1716

Jurnal Ergonomi Indonesia

(The Indonesian Journal of Ergonomic)

Vol.3, No.1 : 1 Januari-Juni 2017

Environments. Berkeley:

University of California 